\title{
Trastuzumab in combination with gemcitabine and vinorelbine as second-line therapy for HER-2/neu overexpressing metastatic breast cancer
}

\author{
ALESSANDRO MORABITO $^{1}$, RAFFAELE LONGO ${ }^{1}$, DOMENICO GATTUSO ${ }^{1}$, GUIDO CARILLIO ${ }^{1}$, \\ CRISTIAN MASSACCESI ${ }^{2}$, LUIGI MARIANI ${ }^{3}$, PAOLA BONGINELLI ${ }^{1}$, SCOLASTICA AMICI $^{1}$, LIVIA DE SIO ${ }^{1}$, \\ MASSIMO FANELLI $^{1}$, FRANCESCO TORINO ${ }^{1}$, MAURIZIO BONSIGNORI ${ }^{2}$ and GIAMPIETRO GASPARINI ${ }^{1}$ \\ ${ }^{1}$ Division of Medical Oncology, San Filippo Neri Hospital, Rome; ${ }^{2}$ Division of Medical Oncology, Ospedali Riuniti, \\ Ancona; ${ }^{3}$ Institute of Biometry and Medical Statistics, University of Milan, Milan, Italy
}

Received March 8, 2005; Accepted June 9, 2005

\begin{abstract}
The aim of this study was to evaluate the safety and efficacy of combined treatment with trastuzumab $(\mathrm{T})$, gemcitabine (gem) and vinorelbine (vin) as second-line therapy for HER-2 overexpressing metastatic breast cancer, pretreated with anthracyclines and/or taxanes and/or trastuzumab. Eligible patients had HER-2/neu-positive disease (IHC $2+$ or $3+$ ), performance status (PS) $\leq 2$ and normal L-VEF. Patients were treated with weekly $\mathrm{T}(4 \mathrm{mg} / \mathrm{kg}$ on day 0 , then $2 \mathrm{mg} / \mathrm{kg})$, in combination with gem $\left(800 \mathrm{mg} / \mathrm{m}^{2}\right)$ and vin $\left(25 \mathrm{mg} / \mathrm{m}^{2}\right)$ on days 1 and 8 , every 21 days. Patients were restaged every 3 cycles. A total of 30 patients (median age, 58 years; range, 41-74) were enrolled in the study. Fifteen patients were HER-2 $3+$ and $26(86.7 \%)$ presented $\geq 2$ metastatic sites. Of the patients, $7(23.3 \%)$ had received trastuzumab as first-line therapy. Treatment was welltolerated with grade 4 neutropenia in 6 patients, grade 3 thrombocytopenia and grade 3 anemia in 1 patient, and grade 3 asthenia in 4 patients. Fifteen patients obtained an objective response (response rate, 50\%; C.I. 95\%, range, 31.3-68.7\%). Among the patients with HER-2/neu $3+$, the response rate was $73.3 \%$. Noteworthy were 4 objective responses observed in patients with brain metastasis. Also, 7 patients had stable disease $(23.3 \%)$. Median progression-free survival was 7 months (range 5-10), and median overall survival was 15 months (range 5-33). T-gem-vin is a safe and active regimen in this subgroup of patients with poor prognosis, and the efficacy of such a schedule was particularly satisfactory in patients with HercepTest $3+$.
\end{abstract}

Correspondence to: Professor Giampietro Gasparini, Division of Medical Oncology, 'San Filippo Neri' Hospital, Via Martinotti 20, 00135 Rome, Italy

E-mail: gasparini.oncology@tiscalinet.it

Key words: trastuzumab, gemcitabine, vinorelbine, metastatic breast cancer

\section{Introduction}

Overexpression of HER-2/neu in breast cancer tumors identifies a subgroup of patients with aggressive disease, frequently with negative hormone receptors and poor prognosis $(1,2)$. Furthermore, tumor amplification of the HER-2 gene has been associated with resistance to a variety of chemotherapeutic agents and tamoxifen $(3,4)$. Trastuzumab is a humanized monoclonal antibody with high specificity for the HER-2 protein (5), which demonstrated activity when used as a single agent in the first- or second-line treatment of metastatic breast cancer (MBC) $(6,7)$ and in combination with chemotherapy (8-10). In a randomized controlled trial of first-line trastuzumab plus chemotherapy in women with HER-2/neu-positive MBC, the combination of trastuzumab and chemotherapy significantly improved time to progression, overall response rate, duration of response and overall survival compared with chemotherapy alone (11). Moreover, such a combination also determined a significant improvement in quality of life compared to standard chemotherapy (12). There was, however, an unacceptably high rate of cardiotoxicity in patients concurrently treated with doxorubicin and trastuzumab, which limited the use of such a combination in clinical practice. This led to the development of alternative trastuzumab-based combinations for HER-2/neu-positive MBC. Several studies have assessed the antitumoral activity and tolerability of the trastuzumab and taxanes combination, an active first-line therapy for this setting of patients (10-14). However, when first-line chemotherapy fails, non-crossresistant treatments with minimal toxic effects that could be easily administered on an outpatient basis are warranted. Preclinical data suggest that the combination of trastuzumab with the antimetabolite gemcitabine or the semisynthetic vinca alkaloid vinorelbine has additive or synergistic activity (15). Gemcitabine and vinorelbine have demonstrated satisfactory antitumoral activity as single agents in metastatic breast cancer (16) and, due to the substantial antitumoral activity of the two drugs, different mechanisms of action and favorable toxicological profile, their combined use has been successfully tested for the palliative treatment of advanced 
breast cancer. The gemcitabine and vinorelbine regimen was an effective and well-tolerated second-line treatment for MBC (17-20) and also active in patients with progressive disease after anthracyclines and taxanes (21). Taken together, these pre-clinical and clinical data suggest that the combination of trastuzumab, gemcitabine and vinorelbine is a potentially active and safe treatment for previously treated patients with HER-2/neu-positive MBC. The aim of the present phase II study was to evaluate the safety and activity of trastuzumab in combination with gemcitabine and vinorelbine (T-gem-vin) as second-line therapy for patients with HER-2/neu overexpressing MBC, pretreated with anthracyclines and/or taxanes and/or trastuzumab.

\section{Patients and methods}

Eligibility criteria. Eligible patients included women with metastatic breast cancer, expressing HER-2/neu at 2 or $3+$ by the HercepTest, who had progressed after a first-line chemotherapy for metastatic disease. Patients had to have discontinued previous treatment for a minimum of 4 weeks. Other eligibility criteria included: measurable disease, age $\leq 75$ years, and performance status $\leq 2$ according to the Eastern Cooperative Oncology Group (ECOG) scale. Furthermore, patients were required to have a life expectancy $>3$ months and adequate organ function, defined as: bilirubin, AST and ALT levels $\leq 1.5$-fold the normal value, $\leq 1.5 \mathrm{mg} / \mathrm{dl}$ serum creatinine levels, $\geq 3,000 / \mathrm{mm}^{3}$ leukocytes, and $\geq 100,000 \mathrm{~mm}^{3}$ platelets. Previous treatment with trastuzumab or hormonal therapy for metastatic disease was allowed. Patients were excluded if they had previous treatment with vinorelbine or gemcitabine, brain metastases as the only site of disease, a positive history for other types of cancer, with the exception of radically resected 'in situ' cervix cancer and nonmelanoma skin cancer, congestive heart failure or concurrent medical illness. Patients with peripheral neuropathy of grade $\geq 2$ or a pregnancy were also ineligible. The protocol was approved by the Institutional Ethics Committee, and written informed consent from all patients was required.

Treatment plan. Patients received vinorelbine at a dose of $25 \mathrm{mg} / \mathrm{m}^{2}$ in $100 \mathrm{ml}$ of $0.9 \%$ normal saline on days 1 and 8 , followed by gemcitabine at a dose of $800 \mathrm{mg} / \mathrm{m}^{2}$ in $250 \mathrm{ml}$ of normal saline as a 30 -min infusion, every 21 days. Trastuzumab was administered at a loading dose of $4 \mathrm{mg} / \mathrm{kg}$ on day 0 of cycle 1 and $2 \mathrm{mg} / \mathrm{kg} /$ week thereafter, following chemotherapy. Trastuzumab was initially administered over $90 \mathrm{~min}$. If well tolerated, subsequent infusions were given over $30 \mathrm{~min}$. Dexamethasone was administered before trastuzumab, and clorphenamine was optional. Each cycle consisted of 3 weeks. A minimum of 3 and a maximum of 8 cycles of treatment had been planned per patient, and trastuzumab treatment was continued for a maximum of 52 weeks in responsive patients.

Instructions for dose modification of drugs were included in the protocol and dependent on the type of toxicity observed and its grade level: on day 1 , in the presence of $\geq 1,500 / \mathrm{mm}^{3}$ neutrophils and $\geq 100,000 / \mathrm{mm}^{3}$ platelets, fulldose chemotherapy was administered. If neutrophils were $<1,500 / \mathrm{mm}^{3}$ or platelets $<100,000 / \mathrm{m}^{3}$, a 1 -week delay was
Table I. Characteristics of the patients.

\begin{tabular}{lc}
\hline & No $(\%)$ \\
\hline Total number & 30 \\
Median age (years) & 58 \\
$\quad$ Range & $41-74$ \\
Performance status & \\
0 & $15(50.0 \%)$ \\
1 & $8(26.7 \%)$ \\
2 & $7(23.3 \%)$
\end{tabular}

Histology

Ductal

Lobular

Others

$1(3.3 \%)$

Estrogen receptor

Positive

$17(56.7 \%)$

Negative

$12(40.0 \%)$

Unknown

$1(3.3 \%)$

HercepTest

$2+$

$15(50.0 \%)$

$3+$

$15(50.0 \%)$

Adjuvant chemotherapy

$18(60.0 \%)$

Adjuvant anthracyclines

$11(36.7 \%)$

First-line chemotherapy

Anthracyclines

Taxanes

$17(56.7 \%)$

Anthracyclines and taxanes

$8(26.7 \%)$

Trastuzumab

$7(23.3 \%)$

Response to first-line CT

Responders

$13(43.3 \%)$

Non-responders

$17(56.7 \%)$

Dominant sites of disease

Viscera

Bone

Soft Tissue

Number of metastatic sites

1

$4(13.3 \%)$

2

$8(26.7 \%)$

3

$8(26.7 \%)$

$\geq 4$

$10(33.3 \%)$

planned. On day 8 , in the presence of $\geq 1,500 / \mathrm{mm}^{3}$ neutrophils and $\geq 75,000$ platelets, full-dose chemotherapy was administered. If neutrophils were $\geq 1,000 / \mathrm{mm}^{3}$ but $<1,500 / \mathrm{mm}^{3}$, full-dose chemotherapy was administered with G-CSF support on days $9-15$. If neutrophils were $\geq 500 / \mathrm{mm}^{3}$ and $<1000 / \mathrm{mm}^{3}$, a $75 \%$ dose of chemotherapy was administered 
Table II. Hematological toxicity (WHO grade).

\begin{tabular}{|c|c|c|c|c|c|c|c|c|}
\hline \multirow[b]{2}{*}{ Toxicity } & \multicolumn{4}{|c|}{ Assessable patients $(\mathrm{n}=30)$} & \multicolumn{4}{|c|}{ Assessable cycles $(n=165)$} \\
\hline & 1 & 2 & 3 & 4 & 1 & 2 & 3 & 4 \\
\hline Leukopenia & $\begin{array}{c}3 \\
(10.0 \%)\end{array}$ & $\begin{array}{c}11 \\
(36.7 \%)\end{array}$ & $\begin{array}{c}9 \\
(30.0 \%)\end{array}$ & $\begin{array}{c}2 \\
(6.7 \%)\end{array}$ & $\begin{array}{c}31 \\
(18.8 \%)\end{array}$ & $\begin{array}{c}44 \\
(26.7 \%)\end{array}$ & $\begin{array}{c}17 \\
(10.3 \%)\end{array}$ & $\begin{array}{c}2 \\
(1.2 \%)\end{array}$ \\
\hline Neutropenia & $\begin{array}{c}1 \\
(3.3 \%)\end{array}$ & $\begin{array}{c}7 \\
(23.3 \%)\end{array}$ & $\begin{array}{c}11 \\
(36.7 \%)\end{array}$ & $\begin{array}{c}6 \\
(20.0 \%)\end{array}$ & $\begin{array}{c}24 \\
(14.5 \%)\end{array}$ & $\begin{array}{c}37 \\
(22.4 \%)\end{array}$ & $\begin{array}{c}22 \\
(13.3 \%)\end{array}$ & $\begin{array}{c}6 \\
(3.6 \%)\end{array}$ \\
\hline Thrombocytopenia & $\begin{array}{c}7 \\
(23.3 \%)\end{array}$ & $\begin{array}{c}1 \\
(3.3 \%)\end{array}$ & $\begin{array}{c}1 \\
(3.3 \%)\end{array}$ & $\begin{array}{c}0 \\
(0.0 \%)\end{array}$ & $\begin{array}{c}20 \\
(12.1 \%)\end{array}$ & $\begin{array}{c}4 \\
(2.4 \%)\end{array}$ & $\begin{array}{c}1 \\
(0.6 \%)\end{array}$ & $\begin{array}{c}0 \\
(0.0 \%)\end{array}$ \\
\hline Anemia & $\begin{array}{c}6 \\
(20.0 \%)\end{array}$ & $\begin{array}{c}7 \\
(23.3 \%)\end{array}$ & $\begin{array}{c}1 \\
(3.3 \%)\end{array}$ & $\begin{array}{c}0 \\
(0.0 \%)\end{array}$ & $\begin{array}{c}36 \\
(21.8 \%)\end{array}$ & $\begin{array}{c}15 \\
(9.1 \%)\end{array}$ & $\begin{array}{c}1 \\
(0.6 \%)\end{array}$ & $\begin{array}{c}0 \\
(0.0 \%)\end{array}$ \\
\hline
\end{tabular}

Table III. Non hematological toxicity (WHO grade).

\begin{tabular}{|c|c|c|c|c|c|c|}
\hline \multirow[b]{2}{*}{ Toxicity } & \multicolumn{3}{|c|}{ Assessable patients $(\mathrm{n}=30)$} & \multicolumn{3}{|c|}{ Assessable cycles $(n=165)$} \\
\hline & 1 & 2 & 3 & 1 & 2 & 3 \\
\hline Phlebitis & $4(13.3 \%)$ & $1(3.3 \%)$ & 0 & $6(3.6 \%)$ & $2(1.2 \%)$ & 0 \\
\hline Vomiting & $8(26.7 \%)$ & $5(16.7 \%)$ & 0 & $14(8.5 \%)$ & $8(4.8 \%)$ & 0 \\
\hline Diarrhea & $4(13.3 \%)$ & $1(3.3 \%)$ & 0 & $5(3.0 \%)$ & $1(0.6 \%)$ & 0 \\
\hline Constipation & $3(10.0 \%)$ & 0 & 0 & $4(2.4 \%)$ & 0 & 0 \\
\hline Mucositis & $2(6.7 \%)$ & 0 & 0 & $2(1.2 \%)$ & 0 & 0 \\
\hline Fever & $5(16.7 \%)$ & $2(6.7 \%)$ & 0 & $12(7.3 \%)$ & $4(2.4 \%)$ & 0 \\
\hline Liver & $4(13.3 \%)$ & $3(10.0 \%)$ & 0 & $11(6.7 \%)$ & $11(6.7 \%)$ & 0 \\
\hline Neuropathy & $4(13.3 \%)$ & 0 & 0 & $5(3.0 \%)$ & 0 & 0 \\
\hline Hypersensitivity & $1(3.3 \%)$ & $1(3.3 \%)$ & 0 & $1(0.6 \%)$ & $1(0.6 \%)$ & 0 \\
\hline Asthenia & $6(20.0 \%)$ & $5(16.7 \%)$ & $4(13.3 \%)$ & $24(14.5 \%)$ & $9(5.4 \%)$ & $4(2.4 \%)$ \\
\hline
\end{tabular}

with G-CSF support on days 9-15. If neutrophils were $<500 / \mathrm{mm}^{3}$ or platelets $<75,000 / \mathrm{m}^{3}$, day 8 chemotherapy was omitted. Oral ofloxacine at a dose of $300 \mathrm{mg}$ b.i.d. and G-CSF support were given in the case of grade 4 neutropenia, until hematological recovery. No dose reduction of trastuzumab was planned. Trastuzumab was stopped if patients developed fevers, chills, allergic reactions, or any grade 3 or 4 toxicities.

Staging and follow-up procedures. Pre-treatment evaluation was performed 1 month before starting therapy and included a complete history and physical examination, complete blood cell counts and serum chemistries, left ventricular eject fraction (LVEF) evaluated by echocardiography and tumor assessment with total body computed tomography, bone scan, skeletal bone X-rays as indicated. During the study, patients underwent clinical examination and routine biochemistry before day 1 , while complete blood cell counts were performed weekly. Response assessment was planned after completion of the 3rd and 6th cycles of chemotherapy, repeating the staging procedures.

Evaluation of response and toxicity. Efficacy and toxicity were evaluated according to World Health Organization
(WHO) criteria. The worst degree of toxicity experienced during the treatment was recorded for each patient.

Statistical methods. Response rate was computed as the proportion of patients with complete or partial tumor response, among all eligible patients. All confidence intervals (CIs) cited are two-sided $95 \%$ exact intervals, calculated by use of the binomial formula. Comparisons between response rates in different strata were made using the Fisher's exact test. Response duration was measured from the day of its initial documentation until disease progression (PD). Progressionfree survival (PFS) was calculated from study entry until last follow-up or evidence of PD; overall survival (OS) was measured from the day of entry until last follow-up or death. PFS and OS curves were estimated by the product-limit method of Kaplan-Meier, whereas comparisons between curves were carried out using the log-rank test.

\section{Results}

Patient characteristics. A total of 30 women were enrolled between September 2001 and June 2004. The main patient characteristics are reported in Table I. The median age of 
Table IV. Treatment results.

\begin{tabular}{lccc}
\hline & $\begin{array}{c}\text { Patients } \\
(\mathrm{n}=30)\end{array}$ & Months & Range \\
\hline Complete response & 3 & & \\
& $(10.0 \%)$ & & \\
Partial response & 12 & & \\
& $(40.0 \%)$ & & \\
Stable disease & 7 & & \\
& $(23.3 \%)$ & & \\
Progressive disease & 8 & & \\
& $(26.7 \%)$ & & \\
Overall response rate & 15 & & \\
& $(50.0 \%)$ & & \\
& & & \\
HercepTest 3+ response rate & $11 / 15$ & & \\
& $(73.3 \%)$ & & \\
Median & & & \\
Response duration & & & \\
Progression-free survival & & & \\
Overall survival & & & \\
\hline
\end{tabular}

patients was 58 years (range 41-74). The ECOG performance status was 0 in 15 patients, 1 in 8 patients and 2 in 7 patients. Fifteen patients were HER-2 $3+$, and 18 patients $(60 \%)$ were treated with adjuvant chemotherapy, containing anthracyclines in 11 cases $(36.7 \%)$. All patients were treated with first-line chemotherapy for metastatic disease: 5 patients with anthracyclines containing regimens, another 17 with taxanes and 8 with combinations of anthracyclines and taxanes. Seven patients received trastuzumab in combination with weekly paclitaxel as first-line chemotherapy, and 13 patients $(43.3 \%)$ obtained a major response to first-line chemotherapy. There were 11 patients $(36.7 \%)$ who had received prior endocrine treatment and 8 patients (26.7\%) treated with palliative radiotherapy for metastatic disease. Upon entry into the study, 25 patients $(83.3 \%)$ had visceral sites of metastasis: $70 \%$ of patients had liver metastases and $23.3 \%$ of patients presented brain metastases. Also, 26 patients $(86.7 \%)$ had $\geq 2$ metastatic sites.

Tolerance. A total of 165 cycles of chemotherapy and 629 administrations of trastuzumab were given to the 30 patients. The median number of cycles of chemotherapy was 6.0 per patient (range 3 to 9) and the median number of trastuzumab administrations was 18 per patient (range 7-50). Reasons for treatment discontinuation were disease progression in 6 patients, medical decision in 2 cases and patient refusal in 1 case. Chemotherapy (102 cycles) $(61.8 \%)$ was given at full dose both on days 1 and 8 . The dose of chemotherapy on day 8 was reduced by $25 \%$ in 46 cycles $(27.9 \%)$ and was withdrawn in 17 cycles $(10.3 \%)$. A 1 -week delay of day 1 and day 8 therapy was made in $46(27.9 \%)$ and 9 cycles

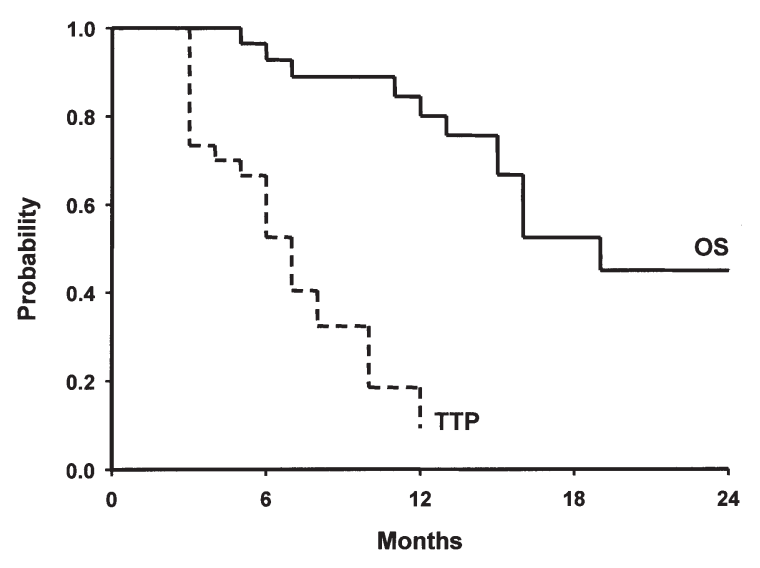

Figure 1. Kaplan-Meier estimated curve of progression free survival (TTP) and overall survival (OS) for all patients $(n=30)$.

$(6.1 \%)$, respectively. G-CSF support was given in 32 cycles $(19.4 \%)$. The planned dose intensity (DI) of gemcitabine was $533.3 \mathrm{mg} / \mathrm{m}^{2} / \mathrm{wk}$, and the median delivered dose was $446.7 \mathrm{mg} / \mathrm{m}^{2} / \mathrm{wk}$. The planned DI of vinorelbine was $16.6 \mathrm{mg} / \mathrm{m}^{2} / \mathrm{wk}$, and the median delivered dose was $14.0 \mathrm{mg} / \mathrm{m}^{2} / \mathrm{wk}$. Therefore, the relative dose intensity was 0.84 for both the drugs. A total of 16 trastuzumab treatments were omitted; therefore, patients received $97.5 \%$ of the planned trastuzumab administrations.

Hematological and non-hematological toxicities are reported in Tables II and III, respectively. Grade 3 and 4 neutropenia occurred in 11 and 6 patients, respectively; two episodes of febrile neutropenia were observed in 2 patients, who were hospitalized and treated with intravenous antibiotic therapy (ceftazidim and amikacin) and G-CSF, with resolution of the toxicity in 2 days. Grade 4 anemia and thrombocytopenia were not observed. The most common non-hematological toxicity was asthenia, which occurred in $50 \%$ of patients, resulting of grade 3 in $13.3 \%$. Reversible hepatic toxicity was observed in 7 patients and moderate phlebitis occurred in 5 patients. Grade 1 peripheral neuropathy was observed in 4 patients. No clinical or instrumental cardiac toxicity was observed.

Response rate and survival. Objective responses and survival data are summarized in Table IV. A complete response was observed in 3 patients $(10 \%)$ and partial response in 12 (40\%) for an overall response rate of $50 \%$ (95\% C.I., 31.3-68.7\%). Seven patients $(23.3 \%)$ achieved disease stabilization lasting for at least 3 months, and 8 patients $(26.7 \%)$ presented progression of disease after 3 cycles. The sites of disease in the complete responders were liver, bone, brain and lymph nodes. Of note, there were 4 objective responses observed in patients with brain metastasis. Moreover, among the 7 patients with progressive disease after first-line chemotherapy with paclitaxel and trastuzumab, there were 2 partial responses and 2 with stable disease were observed with T-gem-vin. No significant difference was found in terms of response rate in relation to the following variables: performance status $(\mathrm{p}=1.000)$, response to first-line chemotherapy $(\mathrm{p}=1.000)$, type of first-line chemotherapy $(\mathrm{p}=0.139)$ and number of metastatic sites $(\mathrm{p}=1.000)$. On the 
contrary, a significant difference in terms of response rate was found in the two subsets of patients who were HER-2 2+ or $3+: 26.7$ vs $73.3 \%$, respectively $(\mathrm{p}=0.02)$. As of November 30, 2004, after a median follow-up of 17 months, 14 patients had died of PD and 16 patients were still alive, of whom 5 remained in response. Median progression-free survival was 7 months (95\% C.I., 5-10 months). The 1-year progressionfree survival was $9.2 \%$, with a median overall survival of 15 months (95\%C.I, 19-33 months); the 1- and 2-year probability of overall survival was 80.0 and $44.9 \%$, respectively. The Kaplan-Meier estimated curves of time to progression and overall survival are reported in Fig. 1.

\section{Discussion}

This is the first phase II study evaluating the safety and efficacy of trastuzumab in combination with gemcitabine and vinorelbine as second-line therapy for patients with HER-2/neu overexpressing MBC. Since the use of combined chemotherapy in MBC is palliative, patients with HER-2/ neu-positive MBC may benefit mostly from combining trastuzumab with agents of moderate toxic effect and satisfactory activity. Taking into account that anthracyclines and taxanes are considered the most active agents in breast cancer and often used in combination as first-line therapy, the search for new effective and non-cross resistant regimens containing trastuzumab with low systemic toxicity and good tolerability is a major area of research. Moreover, an important challenge after the failure of first-line therapy with trastuzumab combined with chemotherapy is to establish whether retreatment with trastuzumab with different, non-cross-resistant cytotoxic agents is capable of restoring response. The above is based on the hypothesis that acquired resistance to therapy is mainly related to chemotherapy, although resistance to trastuzumab is not clearly documented in a clinical setting (23).

The T-gem-vin combination was chosen on the basis of experimental data demonstrating additive or synergistic activity among these drugs (15), and clinical trials confirming the clinical activity and safety of gemcitabine and vinorelbine in previously treated MBC (18-21). In particular, the results of our previously published phase I-II study suggested that the gemcitabine-vinorelbine combination, using the same schedule and dose tested in this study, is an active and well-tolerated second-line therapy in patients pretreated with both anthracyclines and taxanes (22).

Results of the present phase II study indicate that the $\mathrm{T}$-gem-vin combination is an active second-line therapy for patients with HER-2/neu-positive MBC, with a response rate of $50 \%$ and median survival of 15 months. Response rates were highest in patients with tumors HER-2/neu $3+$ by HercepTest $(73.3 \%)$; only 4 patients with tumors HER-2/neu $2+$ by HercepTest presented a partial response to T-gem-vin (26.7\%), confirming the necessity to test the HER-2/neu 2+ tumor for HER-2 amplification by FISH. Of interest are the objective responses observed in $57.1 \%$ of patients with brain metastasis and $28.6 \%$ of patients pretreated with first-line chemotherapy containing trastuzumab.

A favorable toxicological profile was also observed with the T-gem-vin combination, which was well tolerated by the majority of patients. Grade 4 neutropenia occurred only in 6 cycles $(3.6 \%)$ and was associated with infective complications in 2 patients, who were treated with intravenous antibiotic therapy and G-CSF with a prompt resolution. No other grade 4 toxicities were observed. Asthenia was the most common non-hematological toxicity, occurring in $50 \%$ of patients and being of grade 3 in $13.3 \%$. The T-gem-vin combination was not associated with clinical cardiac toxicity nor a significant reduction in $\mathrm{LVEF}$.

In previously treated patients with $\mathrm{MBC}$, other phase II studies have demonstrated response rates of 11 to $15 \%$ with trastuzumab as a monotherapy $(6,7)$ and 24 to $65 \%$ for combinations of trastuzumab with platinum salts (8), taxanes $(10,13,14,24)$, vinorelbine $(25,26)$, or a triplet of trastuzumab with taxanes and platinum salts (27). Preliminary analysis of a randomized study of trastuzumab and paclitaxel vs the same regimen in combination with carboplatin demonstrated an improvement in time to progression with the triplet association (Robert N, et al, Breast Cancer Res Treat 76: abs. 35, 2002). Moreover, other trials that compared polychemotherapy vs. monotherapy for MBC have shown improvement in progression-free survival or overall survival (O'Shaughnessy J, et al, Proc Am Soc Clin Oncol 22: abs. 25, 2003; Seidman AD, et al, Proc Am Soc Clin Oncol 22: abs. 512, 2003) with the use of combined regimens, suggesting that combination chemotherapy could be suitable in a subset of patients with a significant tumor burden, providing superior benefit compared with single-agent therapy (Seidman AD, et al, Proc Am Soc Clin Oncol 22: abs. 512, 2003).

The optimal trastuzumab-based chemotherapy regimen has not been identified, even though there is a trend favoring weekly schedules of cytotoxic agents compared to standard dosages given every 3-4 weeks (32). The T-gem-vin regimen represents an attractive schedule for pretreated MBC patients, due to the favorable toxicological profile of the combination, the absence of cardiac toxicity, and the high percentage of objective responses observed in patients with HER-2 $3+$ tumors $(73.3 \%)$. The activity of this regimen should also be considered of particular interest, taking into account the unfavorable characteristics of patients and previous treatments. In fact, the majority of patients had visceral disease (83.4\%), $\geq 2$ metastatic sites $(86.7 \%)$ and 7 patients presented brain metastasis $(23.3 \%)$.

In conclusion, our data indicate that trastuzumab in combination with gemcitabine and vinorelbine is a welltolerated and effective regimen for patients with HER-2 3+ MBC. The results of this phase II study suggest that the T-gem-vin schedule can be safely used as second-line therapy in women with HER-2-positive MBC and particularly suitable for patients pre-treated with combinations of anthracyclines, taxanes and even trastuzumab.

\section{References}

1. Slamon DJ, Clark GM, Wong SG, Levin WJ, Ullrich A and McGuire WL: Human breast cancer: correlation of relapse and survival with amplification of the HER-2/neu oncogene. Science 235: 177-182, 1987.

2. Querrel N, Wafflart J, Borrichon F, De Mascarel I, Trojani M, Durand M, Avril A and Coinde JM: The prognostic value of c-erbB2 in primary breast carcinomas: a study of 942 cases. Breast Cancer Res Treat 35: 283-291, 1995. 
3. Pegram MD, Finn RS, Arzoo K, Beryt M, Pietras RJ and Slamon DJ: The effect of her-2/neu overexpression on chemotherapeutic drug sensitivity in human breast and ovarian cancer cells. Oncogene 15: 537-547, 1997.

4. Carlomagno C, Perrone F, Gallo C, De Laurentiis M, Lauria M, Morabito A, Pettinato G, Panico L, D'Antonio A, Bianco AR and De Placido S: c-erbB2 overexpression decreases the benefit of adjuvant tamoxifen in early breast cancer without axillary lymph node metastases. J Clin Oncol 14: 2702-2708, 1996.

5. McKeage K and Perry CM: Trastuzumab. Drugs 62: 209-243, 2002.

6. Baselga J, Tripathy D, Mendelsohn J, Baughman S, Benz CC, Dantis L, Sklarin NT, Seidman AD, Hudis CA, Moore J, Rosen PP, Twaddel T, Henderson IC and Norton L: Phase II study of weekly intravenous recombinant humanized anti-p185 HER2 monoclonal antibody in patients with HER2/neu-overexpressing metastatic breast cancer. J Clin Oncol 14: 737-744, 1996.

7. Cobleigh MA, Vogel CL, Tripathy D, Robert NJ, Scholl S, Fehrenbacher L, Wolter JM, Paton V, Shak S, Lieberman G and Slamon DJ: Multinational study of the efficacy and safety of humanized anti-HER2 monoclonal antibody in women who have HER-2 overexpressing metastatic breast cancer that has progressed after chemotherapy for metastatic disease. J Clin Oncol 17: 2639-2648, 1999.

8. Pegram MD, Lipton A, Hayes DF, Weber BL, Baselga JM, Tripathy D, Baly D, Baughman SA, Twaddel T, Glaspy JA and Slamon DJ: Phase II study of receptor-enhanced chemosensitivity using recombinant humanized anti-p185 HER2/neu monoclonal antibody plus cisplatin in patients with HER2/neuoverexpressing metastatic breast cancer refractory to chemotherapy treatment. J Clin Oncol 16: 2659-2671, 1998.

9. Burstein HJ, Kuter I, Campos SM, Gelman RS, Tribou L, Parker LM, Manola J, Younger J, Matulonis U, Bunnel CA, Partridge AH, Richardson PG, Clarke K, Shulman LN and Winer EP: Clinical activity of trastuzumab and vinorelbine in women with HER2-overexpressing metastatic breast cancer. J Clin Oncol 19: 2722-2730, 2001.

10. Seidman AD, Fornier MN, Esteva FJ, Tan L, Kaptain S, Bach A, Panageas KS, Arroyo C, Valero V, Currie V, Gilewski T, Theodoulou M, Moynahan ME, Moasser M, Sklarin N, Dickler M, D'Andrea G, Cristofanilli M, Rivera E, Hortobagyi GN, Norton L and Hudis CA: Weekly trastuzumab and paclitaxel for metastatic breast cancer with analysis of efficacy by HER2 immunophenotype and gene amplification. J Clin Oncol 19: 2587-2595, 2001.

11. Slamon DJ, Leyland-Jones B, Shak S, Fuchs H, Paton V, Bajamonde A, Fleming T, Eiermann W, Wolter J, Pegram M, Baselga J and Norton L: Use of chemotherapy plus a monoclonal antibody against HER2 for metastatic breast cancer that overexpresses HER2. N Engl J Med 344: 783-792, 2001.

12. Osoba D, Slamon DJ, Burhmore M and Murphy M: Effects on quality of life of combined trastuzumab and chemotherapy in women with metastatic breast cancer. J Clin Oncol 20: 3106-3113, 2002.

13. Esteva FJ, Valero V, Booser D, Guerra LT, Murray JL, Pusztai L, Cristofanilli M, Arun B, Esmaeli B, Fritsche HA, Sneige N, Smith TL and Hortobagyi GN: Phase II study of weekly docetaxel and trastuzumab for patients with HER-2-overexpressing metastatic breast cancer. J Clin Oncol 20: 1800-1808, 2002.

14. Tedesco KL, Thor AD, Johnson DH, Shyr Y, Blum KA, Goldstein LJ, Gradishar WJ, Nicholson BP, Merkel DE, Murrey D, Edgerton S and Sledge GW Jr: Docetaxel combined with trastuzumab is an active regimen in HER-2 3+ overexpressing and fluorescent in situ hybridization-positive metastatic breast cancer: a multi-institutional phase II trial. J Clin Oncol 22: 1071-1077, 2004.

15. Bunn PA, Helfrich B, Soriano AF, Franklin WA, Hirsch FR, Varella-Garcia M, Baron A, Zeng C and Chan DC: Expression of HER-2/neu in human lung cancer cell lines by immunohistochemistry and fluorescence in situ hybridization and its relationship to in vitro cytotoxicity by trastuzumab and chemotherapeutic agents. Clin Cancer Res 7: 3239-3250, 2001.
16. Carmichel $\mathrm{J}$ and Walling J: Advanced breast cancer: investigational role of gemcitabine. Eur J Cancer 33 (suppl 1): S27-S30, 1997.

17. Gasparini G, Caffo O, Barni S, Frontini L, Testolin A, Guglielmi RB and Ambrosini G: Vinorelbine is an active antiproliferative agent in pretreated advanced breast cancer patient: a phase II study. J Clin Oncol 12: 2094-2101, 1994.

18. Mariani G, Tagliabue P, Zucchinelli P, Brambilla C, Demicheli R, Villa E, Marchianò A, Valagussa P, Bonadonna G and Gianni L: Phase I/II study of gemcitabine in association with vinorelbina for metastatic breast cancer. Breast Cancer Res Treat 70: 163-169, 2001.

19. Nicolaides C, Dimopoulos MA, Samantas E, Bafaloukos D, Kalofonos C, Fountzilas G, Razi E, Kosmidis P and Pavlidis N: Gemcitabine and vinorelbine as second-line treatment in patients with metastatic breast cancer progressing after first-line taxane-based chemotherapy: a phase II study conducted by the Hellenic Cooperative Oncology Group. Ann Oncol 11: 873-875, 2000.

20. Valenza R, Leonardi V, Gebbia V and Agostara B: Gemcitabine and vinorelbine in pretreated advanced breast cancer: a pilot study. Ann Oncol 11: 495-496, 2000.

21. Stathopoulos GP, Rigatos SK, Pergantas N, Tsavdarides D, Athanasiadis I, Malamos NA and Stathopoulos JG: Phase II trial of biweekly administration of vinorelbine and gemcitabine in pretreated advanced breast cancer. J Clin Oncol 20: 37-41, 2002.

22. Morabito A, Filippelli G, Palmeri S, Cascinu S, Ferraù F, Zagonel V, Gattuso D, Catalano V, Capaccetti B, Franciosi V, Accurso V, Scinto F and Gasparini G: The combination of gemcitabine and vinorelbine is an active regimen as second-line therapy in patients with metastatic breast cancer pretreated with taxanes and/or anthracyclines: a phase I-II study. Breast Cancer Res Treat 78: 29-36, 2003.

23. Tripathy D, Slamon DJ, Cobleigh M, Arnold A, Saleh M, Mortimer JE, Murphy M and Stewart SJ: safety of treatment of metastatic breast cancer with trastuzumab beyond disease progression. J Clin Oncol 22: 1063-1070, 2004.

24. Gori S, Colozza M, Mosconi AM, Franceschi E, Basurto C, Cherubini S, Sidoni A, Rulli A, Bisacci C, De Angelis V, Crinò L and Tonato L: Phase II study of weekly paclitaxel and trastuzumab in anthracycline- and taxane-pretreated patients with HER2-overexpressing metastatic breast cancer. Br J Cancer 90: 36-40, 2004.

25. Jahanzeb M, Mortimer JE, Yunus F, Irwin DH, Speyer J, Koletsky AJ, Klein P, Sabir T and Lronish L: Phase II trial of weekly vinorelbine and trastuzumab as first-line therapy in patients with HER2+ metastatic breast cancer. The Oncologist 7: 410-417, 2002.

26. Burnstein HJ, Harris LN, Marcom PK, Lambert-Falls R, Havlin K, Overmoyer B, Friedlander RJ, Gargiulo J, Strenger R, Vogel CL, Ryan PD, Ellis MJ, Nunes RA, Bunnel CA, Campos SM, Hallor M, Gelman R and Winer EP: Trastuzumab and vinorelbine as first-line therapy for HER2-overexpressing metastatic breast cancer: multicenter phase II trial with clinical outcomes, analysis of serum tumor markers as predictive factors, and cardiac surveillance algorithm. J Clin Oncol 21: 2889-2895, 2003

27. Pegram MD, Pienkowski T, Northfelt DW, Eiermann W, Patel R, Fumoleau P, Quan E, Crown J, Toppmeyer D, Smylie M, Riva A, Blitz S, Press MF, Reese D, Lindsay MA and Slamon DJ: results of two open-label, multicenter phase II studies of docetaxel, platinum salts, and trastuzumab in HER2-positive advanced breast cancer. J Natl Cancer Inst 96: 759-769, 2004.

28. O'Shaughnessy J, Miles D, Vukelja S, Moiseyenko V, Ayoub JP, Cervantes G, Fumoleau P, Jones S, Lui WY, Mauriac L, Twelves C, Hazel GV, Verms S and Leonard R: Superior survival with capecitabine plus docetaxel combination therapy in anthracycline-pretreated patients with advanced breast cancer: phase III trial results. J Clin Oncol 20: 2812-2823, 2002. 